\title{
Talking and driving: Multiactivity in the car
}

\author{
LORENZA MONDADA
}

Abstract

Car conversations constitute a perspicuous setting, characterized by multiactivity (i.e., by an engagement in multiple simultaneous activities, as talking and driving). Based on a corpus of videorecordings of various naturally occurring car journeys, the paper focuses on the way in which participants coordinate their multiactivity in either convergent or divergent ways. It shows how they mobilize various embodied multimodal resources, such as talk, gesture, gaze, head movements, and body postures in order to display their current engagement in one or more activities, in a way highly sensitive to the sequential organization of talk.

Keywords: car conversations; conversation analysis; multiactivity; multimodality; sequentiality; convergent versus divergent action

\section{Introduction}

In car journeys, drivers and passengers engage in various social activities, which are not simply related to moving from one place to another. The car is a social space within which people spend large amounts of time every day and perform a range of activities (Laurier et al. 2008). Thus, it is quite usual for people to phone (Esbjörnsson et al. 2007), to do office work (Laurier 2004), to read newspapers, to eat, as well as to engage in various conversational activities, such as chatting, spreading news, speaking about politics, interrogating children about their homework, exchanging confidences, etc. Other activities concern the management of the journey, such as searching for a parking space (Laurier 2005), giving directions, and deciding the itinerary (Mondada 2005, 2007a; De Stefani and Mondada 2007; Brown and Laurier 2005; Haddington 2010; Haddington and Keisanen 2009).

Existing naturalistic studies have pointed to the variety of everyday activities that are performed in cars. This paper describes the way in which 
conversational activities - such as chatting, telling stories or planning things to do - are carried out in an orderly intertwined way along with driving activities. This timed coordination of various simultaneous activities constitutes what I call multiactivity. The paper focuses on the detailed organization of the convergent versus divergent conducts participants adopt when collectively coordinating the multiple simultaneous activities in which they are engaged.

In section 2, the paper discusses the issue of multiactivity as treated in the literature. Then, in section 3, it proposes an analysis of multiactivity in a multiparty car conversation, showing the methodic way in which a driver first overhears and then engages in the conversation of her passengers. The paper focuses on various configurations in which passengers and drivers either converge and align in organizing their talk and their driving (section 4) or diverge and disalign in managing their activities (section 5). A final analysis, in section 6 , shows that convergent and divergent organization of driving and talking conducts can be exploited in an occasioned way by participants as resources for managing dispreferred sequences of talk. In sum, on the basis of a corpus of naturalistic video-recorded car conversations, the paper aims to explore the systematic organization of multiactivity and its embeddedness within the sequential order of talk and action.

\section{The organization of multiactivity}

Participants engaged in interaction often perform more than one activity: this is a common feature of many social settings that has been variously labeled in the literature as "multitasking" or "multiactivity," and has been discussed in terms of simultaneous activities, overlapping activities, concurrent activities, parallel activities, primary and secondary activities, and polychronic time use - often implying fragmentation, discontinuities, interruptions of the current main activity. The phenomenon has been recognized as a pervasive feature of domestic as well as workplace settings; it has been studied within various perspectives, within psychology, time-use research in economy, sociology of work, $\mathrm{CSCW}$, and information technology design (see for example Floro and Miles 2003; Kenyon 2008; Gonzales and Mark 2004; Datchary and Licoppe 2007) on the one hand, and within workplace studies and conversation analysis on the other (C. Goodwin 1984; M. H. Goodwin 1996; Heath and Luff 1992, 1996, Mondada 2011).

Multitasking in cars has been investigated mostly from a psychological and experimental perspective addressing issues of risk and safety. Studies have focused on various tasks - such as talking, text-messaging, but mostly cellphoning - performed during driving and implying different amounts of "workload" or "cognitive overload." Generally speaking, multitasking in cars has been considered negatively, in terms of "distraction" or "deficit" in alloca- 
tion of attention, or even of "impairment" of driving performance (cf. Recarte and Nunes 2003; Strayer and William 2001; Strayer and Drews 2007). The impact of co-present conversation in multitasking has been variously evaluated: on the one hand, demanding conversations are considered as a significant distraction for the driver (Gugerty et al. 2004; McCarley et al. 2004); on the other hand, conversations have been considered as having a positive effect, passengers being able to offer alerting comments and to maintain driver situation awareness (Charlton 2009). In the latter case,

the critical difference between a cell phone conversation and an in-vehicle conversation revolves around this shared awareness of the driving context. That shared awareness leads to the prediction that in-vehicle conversation will not have the same detrimental impact on driving performance that cell phone conversations have. It also opens the possibility for in-vehicle conversation to have a positive impact on driving performance. (Drews et al. 2008: 393)

The impact is less problematic when either the passenger reduces the conversational demand on the driver (what has been called the conversation suppression hypothesis), especially in the most demanding urban environments (Crundall et al. 2005), or when "the passenger adopts the driving task as part of the overall joint activity in which driver and passenger are mutually engaged" (Drews et al. 2008: 394). These considerations encourage critical appraisal of the methodology used for measuring these effects: most of the experimental settings involve word games or verbal tasks very different from natural conversation. Actually, almost none of these psychological studies use recorded naturalistic conversation and ethnographic observations (Rakauskas et al. 2004 invoke natural conversations but use a list of questions; Crundall et al. 2005 although claiming to use "naturalistic data" use video-recordings of a conversational game, with drivers and partners competing against each other to win points; Charlton 2009 uses an experimental setting with a driving simulator and a set of conversation cards containing topics for discussion). Conversation analytic studies of social activities in cars are still scarce, with the notable exceptions of Laurier (2004), Nevile and Haddington (2010) and Haddington and Rauniomaa (2011).

Within a conversation analytic perspective, the issues of multitasking in cars can be reframed by focusing on the detailed ways in which participants actively define the activities in which they engage, finely coordinate their switches from one activity to the other, suspend a current activity and resume it, and converge or diverge in organizing their multiple activities. The aim is not to evaluate multitasking generically as interrupting or fragmenting the current activity, but to describe the methodic practices through which changes between foregrounded and backgrounded activities, emergent contingencies, and sudden events are dealt with by the participants. Likewise, the issue is not to point to unsafe or risky practices of multitasking, but to study the emic 
way in which participants themselves orient to one activity as more demanding than another, requiring or not unilateral or convergent full engagement. Moreover, current literature on multitasking suffers from not having adequate data documenting activities in their situated multimodal details as they unfold in time and in context. Data video-recorded in social settings among participants involved in their everyday travels document multiactivity as it happens, in both a methodical and an indexical way, and as treated by the participants themselves.

In this paper, I prefer the term multiactivity, used to some extent within conversation analysis and workplace studies, rather than multitasking, used in the above-mentioned literature, to refer to multiple simultaneous courses of action that can be variously related, have a specific sequential organization, and be coordinated. Examples of multiactivity can be found in dinner conversations, where participants are engaged in talking and eating (Mondada 2009a), in call centers, where call-takers speak on the phone and simultaneously use their computer to fill in forms or to search for information (Mondada 2008), in surgery demonstrations, where the surgeon operates on a patient and describes the procedure (Mondada 2007b, 2011). Within conversation analysis and ethnomethodology, these phenomena have been dealt with both in workplace settings and in everyday settings.

Workplace studies (Luff et al. 2000) have focused on complex work environments, described as "centers of coordination" and "shared workspaces" by Suchman (1997), characterized by multiactivity: "The Op Room as a single, shared workspace can be more adequately understood as a place for the successive divergence, convergence, and re-alignment of multiple, shifting lines of activity" (Suchman 1997: 54). The terms "multiactivity settings" (Goodwin and Goodwin 1996: 400) and "multi-focused settings" (M. H. Goodwin 1996: 453) have also been used, and contrasted with single-focused face-to-face encounters traditionally studied by the literature. These multiactivity settings are characterized by the fact that various activities are going on simultaneously, within multiple participation frameworks and within complex ecologies, where participants are dispersed in fragmented spaces and multiple information sources are constantly used by them (such as screens, computers, documents, and other artefacts).

Within these settings, specific modes of activity coordination have been described, characterized by the engagement of individuals in multiple activities (such as speaking on the phone and pursuing the interaction with a co-present colleague), multiple orientations towards various objects and persons within monitoring activities, "double duty activities" producing utterances and actions designed simultaneously for different recipients (Luff and Jirotka 1998). More particularly, Heath and Luff $(1992,1996)$ describe in detail the way in which personnel in control rooms engaged in their independent activity simul- 
taneously monitor others' conduct, overhearing and overseeing their colleagues' actions in order to converge and collaborate with them. A number of workplaces have been described in these terms, such as control rooms in airports (M. H. Goodwin 1996; Goodwin and Goodwin 1996; Suchman 1997) and underground transportation (Heath and Luff 1992, 1996), trading rooms (Heath et al. 1995), operating rooms in surgery (Mondada 2007b, 2011), and call centers (Mondada 2008).

This complex web of activities does not solely characterize the workplace setting, but can also be observed in SUPPRESS of activity, such as face-to-face conversation. Goodwin used the term "multiactivity setting" very early on (1984: 227) to describe a storytelling episode in which recipients not only pay attention to its structure but also "manage shifting but concurrent involvement in other activities" (1984: 225). Participants can display their complete engagement in the telling but they can also organize their parallel involvement in multiple activities, such as eating, passing dishes, caring children, as well as being fully occupied with non-conversational activities. Goodwin describes how conversing and eating can be designed to be performed simultaneously but also to be interrupted and abandoned in favor of the other. These alternating forms of engagement and disengagement are displayed by the distribution of gaze, either focused on the storyteller or looking away while responding to the demands of concurrent activities such as eating. Even when participants disengage from talk, their changes of body position or gaze shifts occur through orienting very precisely to the boundaries of the multi-unit turn of the story, showing that participants align with it as the main activity going on.

These studies on the coordination of multiple activities in the workplace or in everyday life show how participants manage them in a methodic way, highly sensitive to the sequential organization of talk. When participants momentarily disengage from talk, switch to another activity, perform two activities simultaneously, they do it in a systematic way, by orienting to the timed positions at which these transitions occur - paying special attention to newly initiated sequences, absent second pair parts, pursued responses, repairs, inserted sequences, etc. In this sense, multiactivity reveals the real-time endogenous analysis participants constantly achieve within conversation and within other actions, monitoring them in order to exploit methodically sequential positions as occasioning and even affording complex coordination. In this paper, we focus on such timed coordination embedded within sequential organization. We focus on the way in which driving and talking are achieved within a finely-tuned coordination between drivers and passengers, while they both engage and disengage from these activities, paying special attention to the way in which they do that in a convergent or divergent way, in an aligned or disaligned way.

Multiactivity not only exploits features of temporal organization but also relies on spatial configurations and bodily arrangements. Workplace studies 
have insisted on the complex ecology of shared work spaces; studies of multimodality and gesture have insisted on the importance of spatiality for the organization of interaction. Talk and other conducts unfold in "contextual configurations" (Goodwin 2000), which are defined by the participants' orientations to various "semiotic fields" made locally relevant, such as the material environment, graphic fields, artefacts, embodied movements, and spoken language. The importance of the spatial disposition of these resources has been emphasized by a focus on the embodied dimension of participation frameworks and on the spatial arrangement of the bodies that enable focused interactions (Goffman 1963; Goodwin and Goodwin 2004). The notions of "F-Formation" (Kendon 1990) or "interactional space" (Mondada 2005, 2009b) focus both on the material environment in which social actions are anchored - comprising its physical constraints and the artefacts included in it - and on the dynamic, flexible, and praxeological nature of the space actively constituted by the movements, actions, glances, and object manipulations of the participants.

Car conversations constitute a particularly complex interactional space, since they are configured by side-by-side and front-and-back sitting positions of the participants and by the way in which they inhabit the car-space with their movements, body torques, lateral and peripheric glances; by the visual field of the road constituted through the mobilization of gazes not only through front and lateral windows but also rear-view mirrors; and by the constantly changing position of the car within the road and landscape. Embodied participation frameworks in car conversations are achieved by the concurrent mobilization of multimodal resources, such as gaze, head movements, and bodily postures displaying fast-changing relevances and foci of attention. More particularly, the side-by-side position constrained by the material environment of the passenger cell occasions body-torque positionings (Schegloff 1998) during conversation that display double orientation towards the frontal visual field of the road and towards the co-participant. This double orientation has been observed in medical consultations as well, where the doctor "is simultaneously engaged in at least two courses of action, one oriented toward the desk and the other toward the patient" (Robinson 1998: 104). This paper shows how parallel versus alternating, inclusive versus exclusive, orientations towards driving on the road and towards chatting with co-participants are managed by both drivers and passengers in convergent or divergent ways, establishing common or distinct contextual configurations for their actions, flexibly foregrounding or backgrounding them, and even exploiting these multiple configurations to manage delicate moments in talk.

My analyses are based on a corpus of video-recordings of eight car journeys (five with at least two participants, and three with the driver alone, not considered here) for a total of six hours. ${ }^{1}$ Participants agreed to be videotaped by two cameras: one was placed on the dashboard, facing the participants and captur- 
ing the passenger cell; the other was placed on the back seat, capturing the road in front of the driver. These multi-source videos permit us to document the bodily orientations, head movements and gaze, taking into account the space of the car cell as well as the external visual field of the participants.

\section{A first example of multiactivity: Multiple and changing participation frameworks}

Multiactivity is a form of simultaneous organization that is highly flexible, constantly changing, moment by moment, adapting to the contingencies of the talk and the road. In multi-party car conversations, these changes affect the embodied participation framework and the interactional space in which the participants are distributed.

A first excerpt illustrates this flexibility, showing that different forms of multiactivity coordination are constantly negotiated and switched. We join the action as the mother, Laura, drives her daughter Stéph and two young friends, Isa (sitting behind Stéph) and Sara (sitting behind Laura).

(1) (homework_5.51-6.45/arr16.00)2

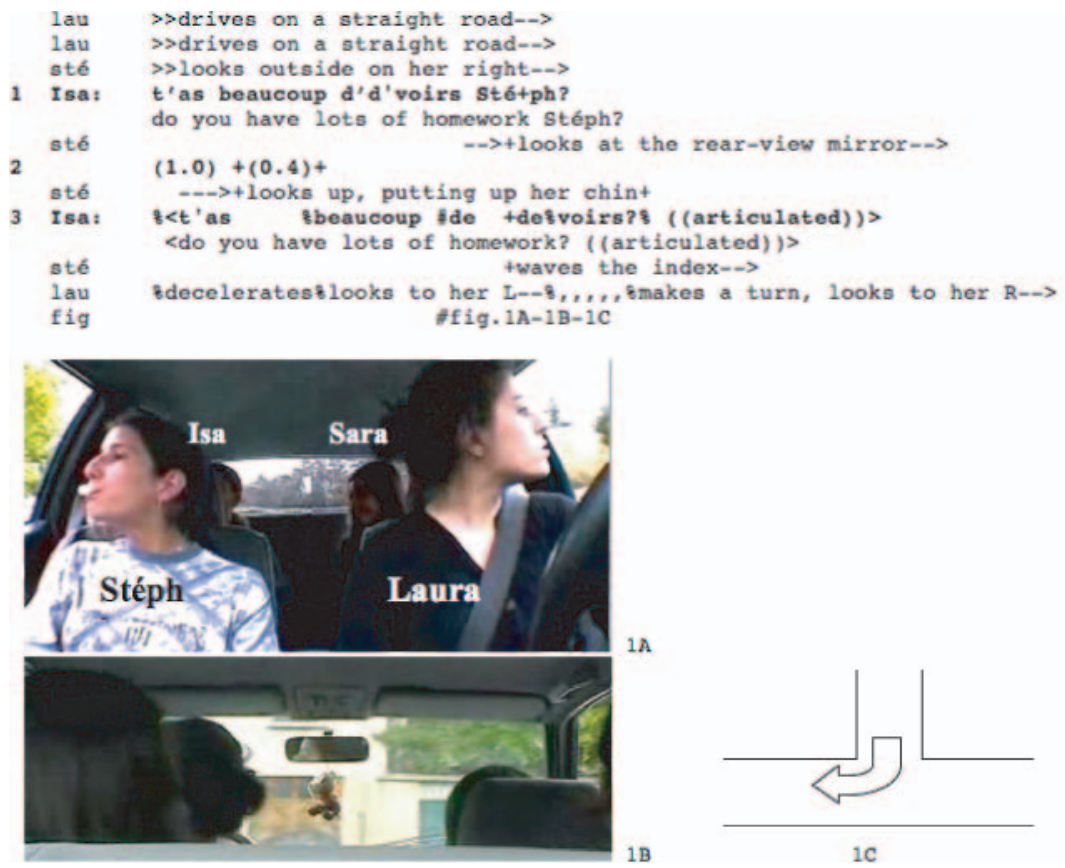


5 Sar: $t^{\prime a s} d^{\prime} l a$ chance, moi j'ai un dé ès you're lucky,

lau $\rightarrow$ \$looks in front of her and accelerates on a straight clear roadm 6 de latin vendre[di.]

[j'les] fais en anes heuret ih $\mathrm{gh}$

[I do] them in one hour ih HH

fig -.> looksfturns to Stéph $\rightarrow$

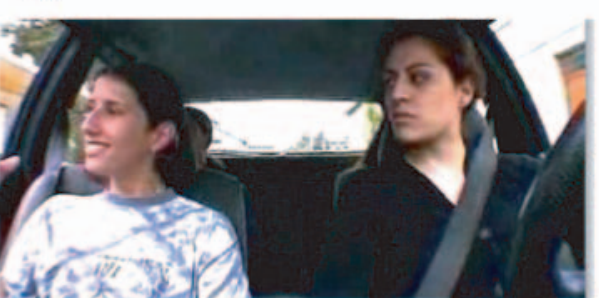

$2 \mathrm{~A}$

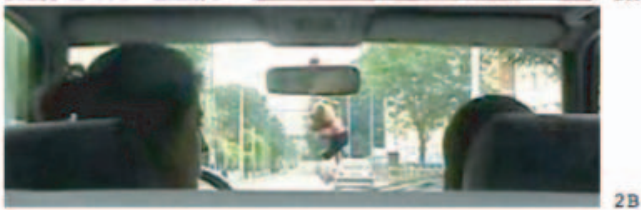

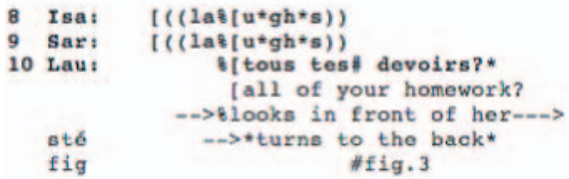

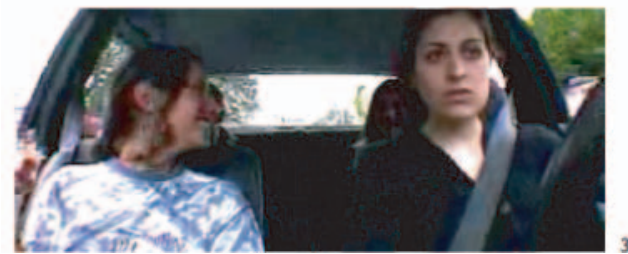

11 sté: ((laughs))

12 Lau: to*us tes \#d'voirs?

all of your homework?

sté *turns to Lau-->

fig \#fig. $4 \mathrm{~A}-4 \mathrm{~B}$ 

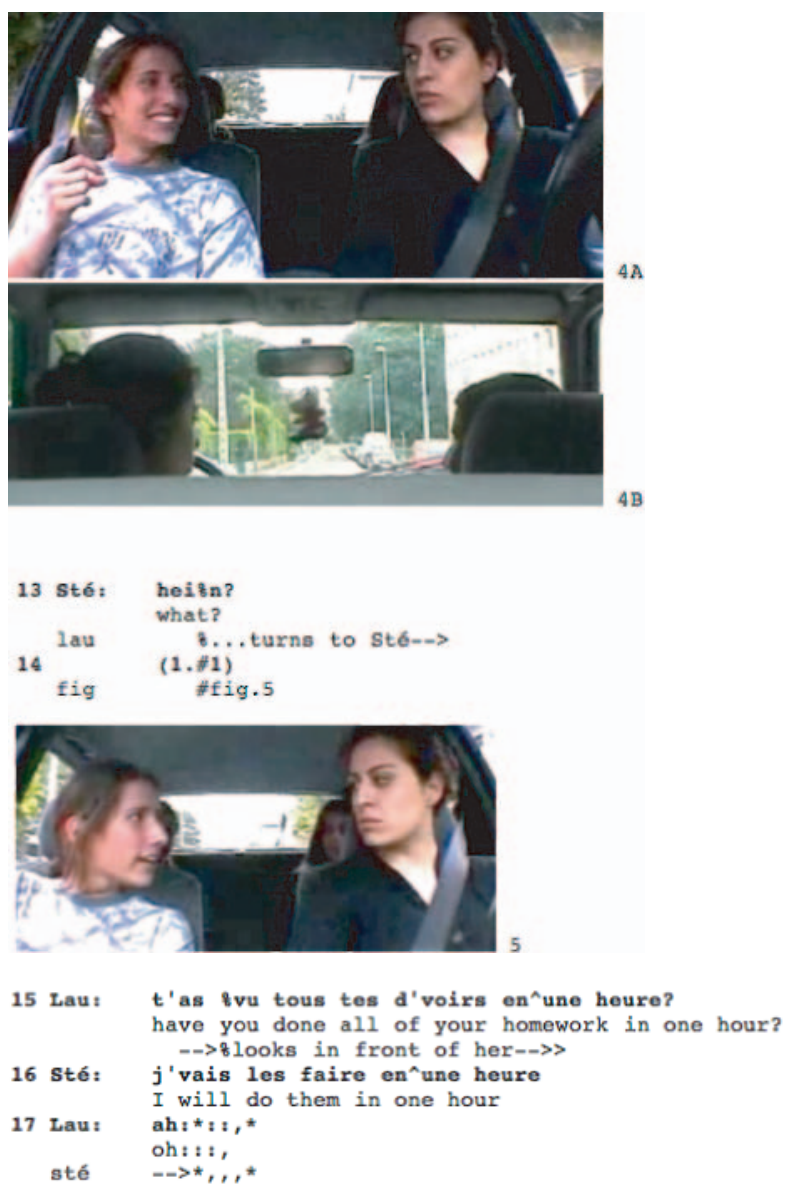

In this excerpt, multiple activities and changing participation frameworks are observable. At first, the participants are engaged in two different activities (the girls are chatting and laughing, the mother is driving) and have their attention focused on different objects (Stéph on the landscape through the window and then on her friends through the lateral rear-view mirror; Laura on the road, as she approaches a crossroad and makes a turn on the left - Figure 1C) although overhearing and overseeing each other. Then, as Laura engages on a straight road, she displays her attention to an announcement made by Stéph about her homework and turns to her, engaging in serious talk and mutual gaze with her. Both activities, driving and talking, are successively organized in divergent and convergent ways, reshaping the participation frameworks and exploiting the constrained space of the car and the disposition of the participants in ways that accountably exhibit their modes of participation. 
In line (1), Isa initiates a new topic by asking a question of Stéph about her homework. At that moment, Stéph is looking through the window, on her right. As Isa mentions her name at the end of her turn, Stéph turns her gaze to the lateral rear-view mirror, through which she can see Isa sitting behind her. She then initiates a repair to the question, with a movement of her head, putting up her chin (line 2), since her mouth is full of the gum she is chewing (Figure 1A). Isa repeats her question in a more articulated way (line 3) and Stéph answers without saying a word, by waving her index finger in a negative way. At that moment, Laura is approaching a junction (Figures 1B-1C); she looks to the left, then to the right, and makes a big turn; her attention is focused on the road. At the end of this sequence, mother and daughter are facing opposite directions (Figure 1A), engaged in two different activities, driving and chatting, orienting to different relevances - the former to the road in front of her and beside her, the latter to the passengers behind her - adopting divergent body postures.

After the turn, as Laura drives along a straight road, Sara expands the previous sequence, assessing Stéph's situation and contrastively telling her that she has lots of work to do (lines 5-6). In response, Stéph announces that she is very fast in doing her homework (line 7). She initiates laughter (line 7), joined by her friends laughing with her, and she turns back towards them (line 10) increasing her involvement in the laughter (line 11). Stéph's announcement is not only overheard but also responded to by her mother, who turns to her (line 7; Figure 2) and initiates a repair (line 10). Stéph does not respond, occasioning a repeat of the repair initiation (line 12); Stéph herself initiates a repair (line 13), occasioning a new repeat (line 15), to which she finally answers (line 16). Laura's change-of-state token closes the sequence (line 17). During this postsequence, the driver bodily orients to Stéph's action and engages in the conversation with her: she looks at her while Stéph makes the announcement, and then when she replies to her confirmation-seeking question, i.e., in a sequential position where gaze is mobilized to pursue a response (Rossano et al. 2009; Stivers and Rossano 2010). She finally looks again at Stéph when the latter initiates a repair (lines 13-14) and likewise orients her gaze and her body to her mother, maintaining them until the sequence is completed. Thus, whereas in the first sequence the friends are engaged in mutual talk and laughter and the mother is disengaged from that activity, in the post-sequence, mother and daughter are convergently engaged in the conversation.

In this excerpt, participants organize both convergent and divergent activities, which are displayed by different body positions and gaze directions, oriented to mutual attention or to attention towards external objects, shaping different participation frameworks and different contextual configurations (Goodwin 1984, 2000).

Multiactivity typically involves being simultaneously engaged in two or more courses of action, coordinating both of them, usually mobilizing different 
resources, differently distributed within the temporal and sequential organization of these activities.

The organization of these collective activities is sensitive to the temporally changing specificities of the road and landscape environment as well as to the sitting configuration of the participants inside the car. Car space is a constricted environment which favors the relevances of driving activities. Car features designed for the ergonomy of driving, however, such as rear-view mirrors, can be used in a situated way by the passengers as resources for conversation, for securing mutual gaze in a spatial disposition front-to-back. Resources designed for driving are used situatedly as resources for talking.

Gazes, glances, looks are distributed between talk and driving in ways that accommodate both activities or favor momentarily one activity over the other, as well as in ways that favor a convergent, mutual orientation of the participants or divergent, parallel focuses of attention. In car multiactivity, the economy of glances involves accurate distribution of looking at the relevant details of the road and looking at other participants. This distribution is also publicly accountable and oriented to by co-participants, who distinguish between glances addressed at the recipient and glances monitoring the street traffic.

Within this constricted space, parallel simultaneous activities can evolve in changing participation frameworks and are available for overhearing and mutual scrutiny. The mother can format her action as focused on the road, absorbed by driving, but she can also join the other action going on, displaying that she overhears the conversation and orients to its sequential features. Her way of organizing her multiactivity displays multiple membership categories (Sacks 1972): she displays that she is not only a "driver" but also a "coparticipant" in the conversation, and even a "mother," sensitive to some topics in the teenagers' conversation and their moral implications. In this episode, the mother engages in multiactivity, both driving and talking, whereas the girls do not display any particular participation in the driving (as they could do as "co-drivers") and are here mere "passengers."

More generally, multiactivity does not only characterize the driver. Even if she has the responsibility for the journey, other members can collaborate in the drive, share the relevant details of the driver's practice and act as "co-drivers" and not only as "passengers." Multiactivity can be organized as a collective or an individual activity, as a convergent or as a divergent conduct: passengers can join the driver in navigating a way through the traffic or they can focus only on conversation; the driver can drive in silence or join in the conversation.

In the following analyzes, I describe the methodic organization of these configurations, focusing first on convergent conducts (section 4), then on divergent ones (section 5). Finally, a last excerpt shows how convergent and divergent conducts are sensitive to sequential environments characterized by preference and dispreference (section 6). 


\section{Convergent conducts}

Participants in the car journey can organize their actions in a way that exhibits a convergent participation in multiactivity.

In the following excerpt, Bea and Ric are driving to Bea's parents with their baby in the back of the car:

(2) (0809-4.05)
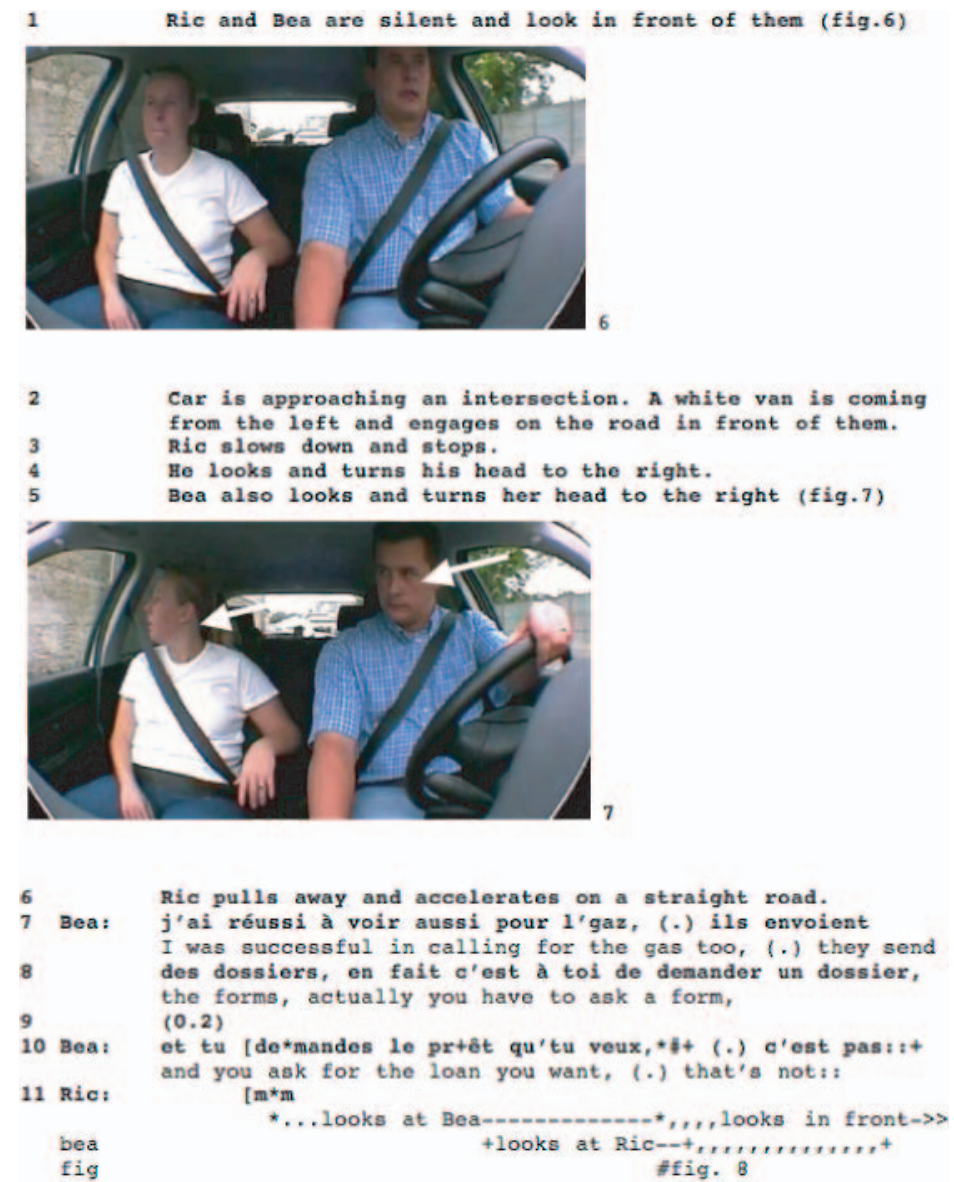

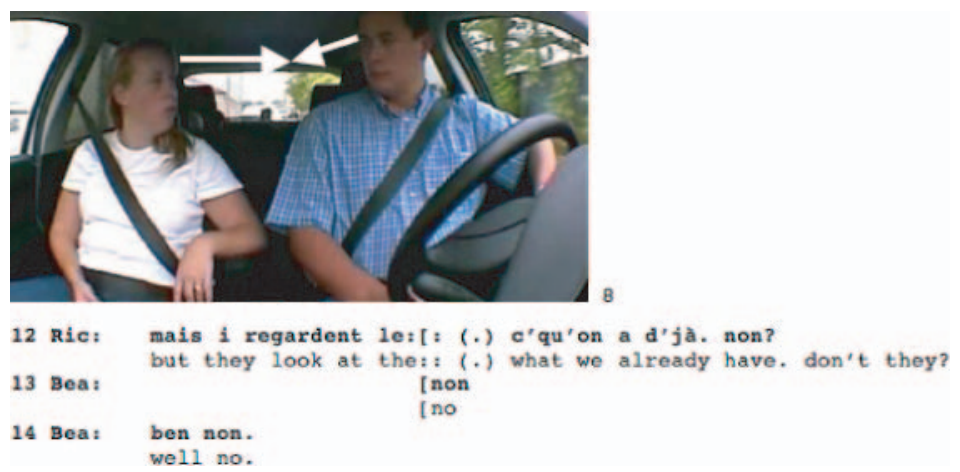

At the beginning of this excerpt, participants are silently involved in the driving activity (Figure 6); at the intersection, they both look at the relevant direction, first Ric, then Bea, aligning after a short delay (Figure 7). They orient together towards the changing relevances of the traffic. Then, when the car accelerates on a straight road, they engage together in talk about their common plans to build a new house (line 7), continuing a topic they initiated before (in a continuing state of incipient talk, Schegloff and Sacks 1973) as Bea produces an informing (lines 7-10) and Ric responds, although minimally (line 11). Their common involvement in talk is made accountable by their mutual glance at TCU completion (line 10) (Figure 8).

This excerpt shows convergent participation first as regards the driving activity, then talking. The organization of convergent engagement and disengagement in the activity (Szymanski 1999) orients to the sequential organization of talk but also to the temporal organization of the journey: it is sensitive not only to the unfolding urban environment, but also to the relevant attention and actions it occasions. In this case, an intersection with a van coming from the left and slowly engaging on the same road occasions a close scrutiny of the road. Multiactivity adjusts to the local categorization of a place treated as absorbing (versus unproblematic), as requesting specific monitoring and decision-taking or not.

In this excerpt, the couple aligns both in participating in the talk and in the driving. In the following sections, I analyze other occurrences of convergent focus of attention, first on the conversation (section 4.1), then on the road (section 4.2).

\subsection{Convergent involvement in conversation: Mutual gaze}

Common engagement in conversation is displayed not only by relevant contributions to the sequential unfolding of talk, but also by exchanges of mutual 
gaze. Since in car conversations the economy of gaze is different from face-toface conversation, gaze being essentially involved in the other activity, driving, the exchanges of mutual gaze are restricted and favor sequential moments in which mutual attention and involvement are particularly expected (cf. Rossano et al. 2009).

The next excerpts provide some occurrences of convergent talk activities characterized by mutual gaze.

In the first one, Peter has just joined Radia, who is driving the car, and jokes about the presence of the video cameras:

\section{(3) (1707c_1.23)}
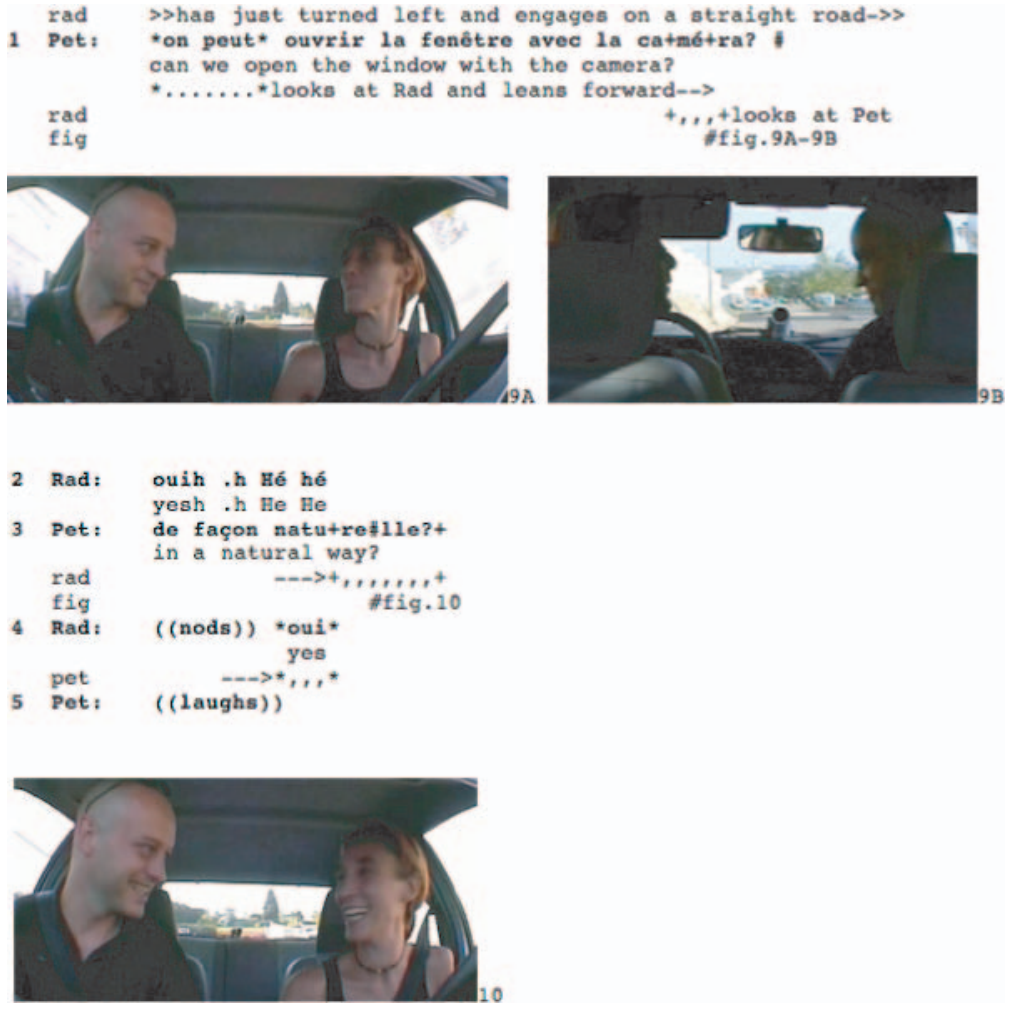

In line 1, Peter asks a question of Radia: he looks at her and leans forward, in a way that makes his glance even more visible for her (Figure 9A-9b). She answers, initiating laughter, and looks at him, maintaining mutual gaze during his delayed completion of his question, which occasions new laughter. Both smile and join in laughter (Figure 10). In this expanded sequence, they engage 
in conversation in a strongly convergent way, displayed by mutual gaze and aligned stances.

A few seconds later, Radia announces that Peter has to sign the authorization form for the video recording:
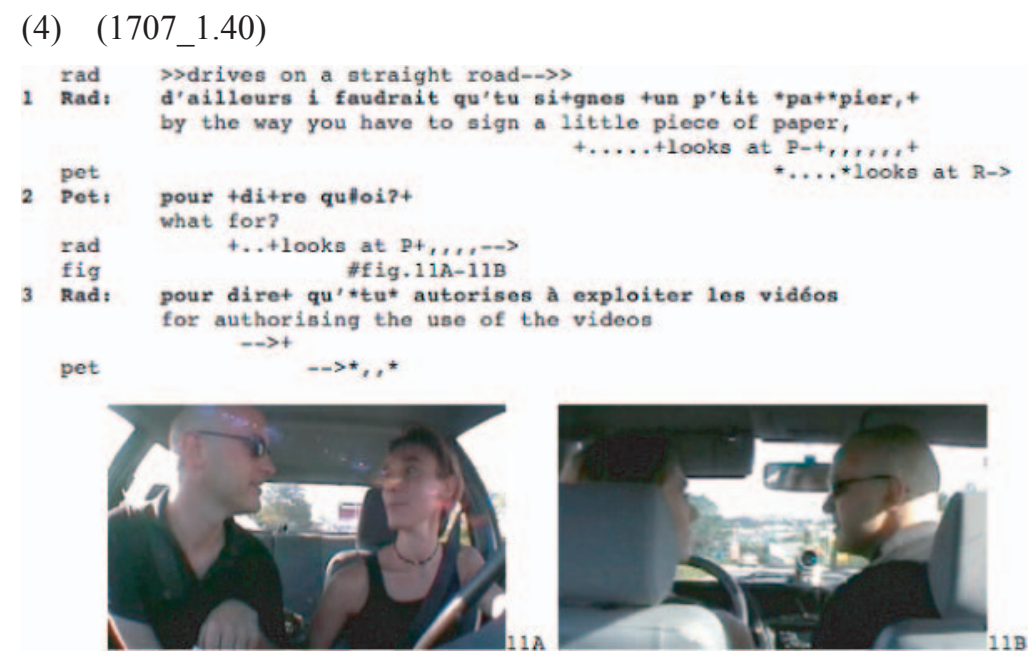

Radia makes a request (line 1) and just after the verb, on the verb's argument, she turns her head towards Peter, who looks at her before turn completion. Instead of aligning with the request, Peter inserts a question-answer sequence (line 2-3), continuously looking at her, leaning in and turning towards her in a body-torque position that momentarily transforms their side-by-side disposition into a face-to-face one. As Radia begins to answer, both retract their gaze.

In these excerpts, participants converge in engaging in talk. By gazing at his/her co-participant while initiating a new sequence and pursuing a response, the driver displays higher engagement in the conversation. In both excerpts, gaze occurs in a crucial sequential position (a first pair part initiating a new sequence) and in context where they drive on an unproblematic stretch of road, large, straight and without traffic. More generally, in the corpus, mutual gaze tends to be systematically positioned, namely, in repair sequences, in topicinitiations, in adjacency pairs involving a specific involvement of the recipient - in environments that deserve more detailed study but confirm previous observations on gaze and sequence organization (Rossano et al. 2009). Moreover, mutual gaze seems to be facilitated in environments characterized by unproblematic driving: all the occurrences shown here occur on straight roads, and in the corpus mutual gaze occurs frequently at stops in front of a red light. As we 
will see below (in section 6), particularities of the driving context may be exploited for talk by positioning certain kinds of actions in these environments, facilitating or obstructing the driver's participation.

\subsection{Convergent involvement in driving: The coordinated suspension of the conversation}

Convergent activities in driving and talking can be manifested in aligned shifts of attention from the conversation to the traffic and vice versa, where participants not only display co-membership as "co-conversationalists" but also as "co-drivers" (when the passenger's conduct aligns with the driver's attention towards the road). The next excerpts present a common sequential pattern, where both participants align in managing the suspension of the ongoing talk and the insertion of a sequence relative to the management of the traffic, before resuming prior talk.

In the following excerpt, Lisa, the passenger, is telling Radia about her doubts concerning her work as a schoolteacher:

\section{(5) (12.55-13.17)}
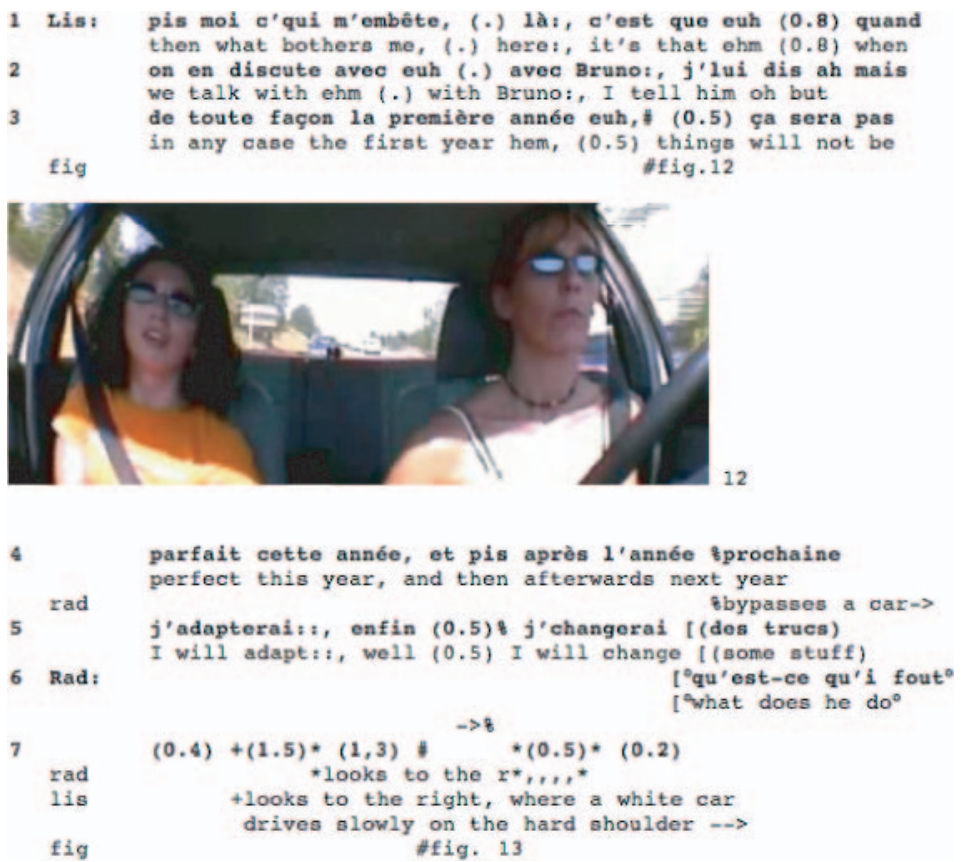

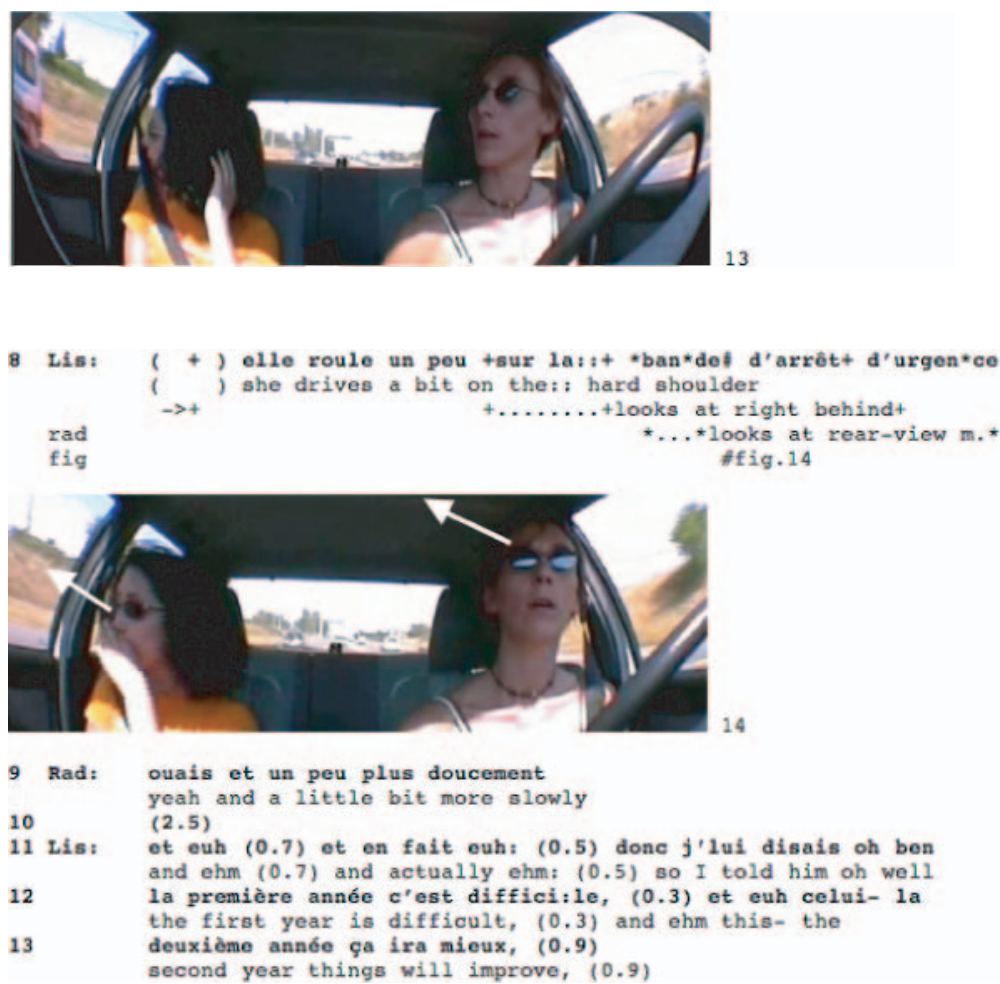

Lisa is telling of her problems as a young teacher not knowing how far she has to prepare her lessons (lines 1-5): her multi-unit turn is not responded to by Radia, who concentrates on the road (Figure 12). In line 6, Lisa is overlapped by Radia making a comment about a white car, which is driving on their right, in the hard shoulder. As they overtake the car, both look on the right (line 7, Figure 13); Lisa produces a noticing (line 8), displaying that she has identified the problem Radia was addressing, and Radia responds (line 9). They display their new common focus of attention, topicalizing it and also looking towards the same object outside. While Lisa does her noticing, she turns again to the white car which is now behind them, and Radia looks at it too, using her rearview mirror (Figure 14).

After a pause, Lisa comes back to her narrative and recycles some of the previous fragments of talk (line 11-13); she orients to the traffic event as a contingent insertion within her talk, which is resumed. In this case, Radia's lower-voiced response cry, produced as talking aloud (line 6), does not only manifest a new focus of attention but also makes her noticing public, in such a way that it is not only available for Lisa but offers her the opportunity to align 
with the driver (cf. Heath and Luff 1992, 1996 for the analysis of similar exclamations making the speaker's focus of attention public and encouraging a colleague to monitor the common environment).

In the next excerpt, a similar insertion sequence is convergently coordinated by both participants. Whereas it was initiated by the driver in the previous excerpt, in this one the passenger self-suspends her narrative in order to insert directions for the driver.

Lisa is talking about the place where she spent the weekend:

(6) (15.07-2.49)
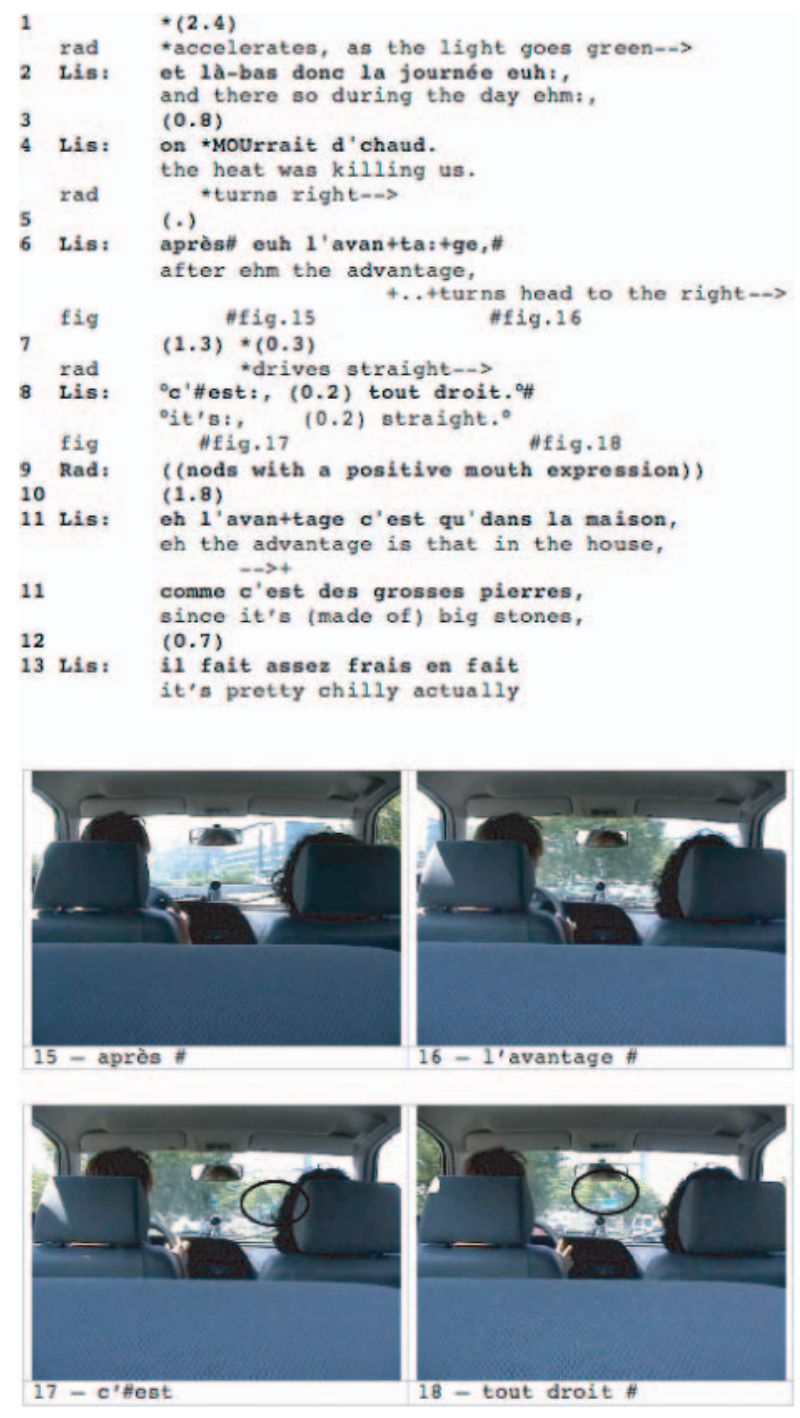
Lisa is describing the hot weather which contrasted with the chilly house where she spent the weekend (lines 2-6). The description started when the car was stopped at a red light, but at line 1 the car moves on, and Radia begins to turn right (line 4). In line 6, Lisa begins a new TCU, which initiates a bipartite clef construction, with a first part (l'avantage "the advantage") projecting a second part beginning with c'est que "it's that." But what follows is not the completion of this syntactic structure: after a pause (line 7), Lisa uses the same construction to do something else; in line 8, she gives an instruction to the driver (c'est:, [0.2] tout droit "it's:, [0.2] straight"). In the meantime, the driver has begun to drive straight and minimally responds with a nod (line 9). Both passenger and driver orient to the fact that they have to take a decision (cf. Haddington 2010), and to the changing landscape around them, allowing for different possible interpretations of the deictic references as they move (Mondada 2005, 2007a).

In this context, both participants align in disengaging from the storytelling and engaging in way-finding through the traffic. The production of Lisa's instruction, c'est (0.2) tout droit "it's:, (0.2) straight" (8) is perfectly matched with the temporality of the car turning and the orientation of the participants in the urban landscape, being uttered exactly at the point where the car is in a position in which the indexical expression tout droit "straight" makes sense.

After the car has taken the right direction, Lisa goes back to her storytelling (line 11), recycling the expression used before and abandoned (l'avantage c'est "the advantage it's that"). The fact that the story and the suspension use the same syntactic form (c'est "it's") is a way for the participants to minimize the interruptive character of their turning to the traffic and switching from a talking activity to a driving one. In this way, they display a double orientation towards the insertion and the continuation, the suspension and the progressivity of talk.

A recurrent pattern is observable in these convergent transitions from a focus on talk to a focus on driving, where the participants align in switching between these activities within an inserted sequence (see Mondada 2005 for a systematic description of this format). The pattern can vary concerning who initiates the switch from one activity to the other or who operates the final resumption, but in all of the cases both participants orient to a problem on the road - the passenger aligning with the focus of attention of the driver, thus acting as a "co-driver." Both orient to the inserted character of the switch and to its possible disruptive consequences on the ongoing talk; in this case, they mobilize various tying techniques to repristinate the previous topical line.

\section{Diverging conducts}

In the previous excerpts, I showed how participants can converge in performing talk and driving. Alternatively, passengers can also not share the driver's attention on the road and continue exclusively and unilaterally to engage in the 
pursuit of the conversation: in this case, participants' conducts diverge, as well as their bodily orientations.

In the next fragment, Radia and Lisa are talking about their weekend plans and a common friend, Jeanne. Approaching a red light, Radia asks a question about Jeanne (line 1). As Lisa answers (line 3), the light turns to green and Radia passes it. After a delayed acknowledgement (line 5) she engages in a highway entrance, with other vehicles coming from the right. During a long silence, she monitors other vehicles circulating parallel to her (line 6), fully engaged with driving, while Lisa stays immobile, without moving her head towards the traffic:

(7) (15.07: 4.25-4.59)
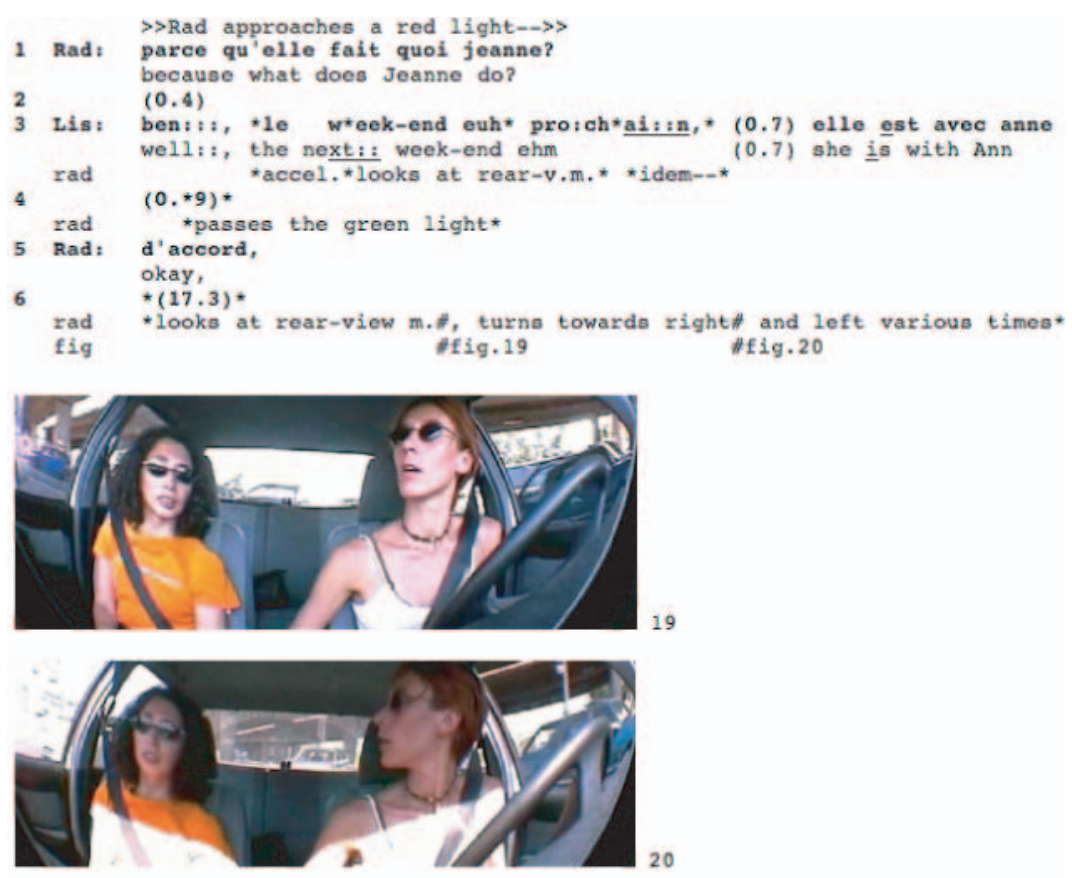

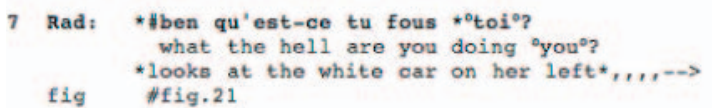

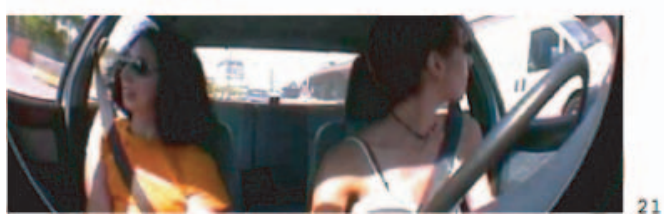




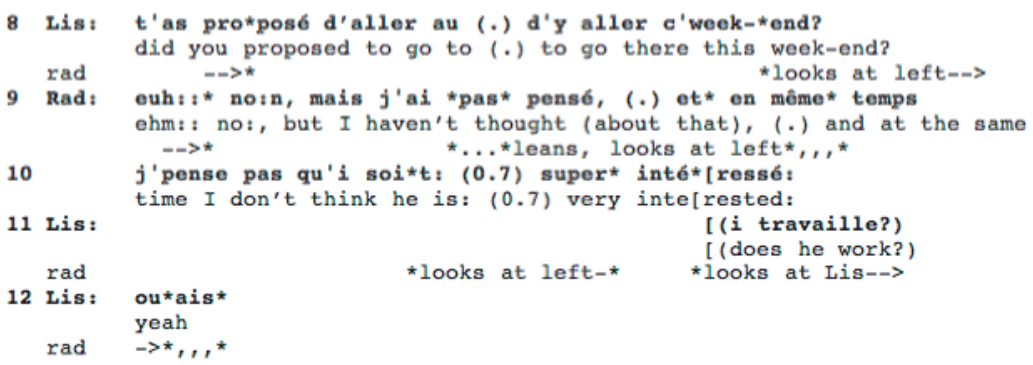

In line 6, Radia engages with a complicated junction and looks at her rear-view mirror a number of times; she produces a delayed receipt token after Lisa's answer (line 7), but does not add any further talk. Instead, her attention is clearly focused on the traffic, monitoring it in a series of glances that mobilize her entire body, leaning and turning in various directions (Figures 19 and 20). During this long pause (17.3 seconds), Lisa remains static, does not align with any of Radia's movements and does not pay visible attention to any outside event. Nevertheless, even if she does not bodily engage in an aligned scrutiny of the traffic, she remains silent, implicitly registering the non-availability of her conversational partner. As a white car slowly overtakes them (line 7), Radia utters a question, directly addressed to it, in a lower voice - a kind of talking aloud, which does not address Lisa (cf. extract 5). Lisa is not looking in the same direction (Figure 21) and she does not respond to this utterance without displaying any hearing or seeing of what is happening. Immediately after Radia's turn, she goes on with the same topic, skip connecting with her own previous turn, and asks her a question (line 10), which Radia promptly answers. At this point, she has overtaken the white car and she is normally engaged on the highway: during this last sequence (lines 10-14) she gazes various times to the left, still monitoring the white car's movements while she talks. At the end of her turn, she turns to Lisa, displaying she is available again for talk.

This excerpt shows that driver and passenger can be engaged in parallel and divergent conducts. Both are performing distinct category-bound activities (Sacks 1972), the passenger talking — or remaining silent — and the driver driving. For a while, the driving activity is accountably displayed by Radia as being exclusive of other activities (cf. Robinson 1998: 103 about similar posture of the doctor fully engaged with reading the records), in a context of heavy traffic. Lisa aligns with the non-talk activity, remaining silent; but she does not align with the driving activity - as she does not visibly join in the monitoring of the traffic. Her body and head orientation remains static and contrasts with the bodily engagement of Radia accountably looking and orienting in various directions. 
Radia joins again the conversation when the obstacle has been overtaken; for a while she continues to be involved in a sustained monitoring of the traffic, as shown by her multiple glances to the left, simultaneously talking to Lisa. Radia's involvement in talk is sequentially sensitive: she initiates a new sequence when the way seems to be clear (line 1), she provides no talk during heavy traffic (line 6) and she is responsive while she retrospectively monitors a vehicle she has just overtaken (line 9). As in the previous excerpts, there is an inversely proportional relation between the degree of involvement in traffic and the degree of involvement in talk: maximal involvement in driving can exclude talk, but other degrees allow a more or less active participation in conversation, which can be reduced to responsive actions in the middle of hard traffic, or expanded to initiating new actions in the context of less demanding traffic conditions.

In the next excerpt, Radia does not attend to Lisa's talk, but after the problem on the road has been solved, she initiates a turn, recycling the previously abandoned topic:

(8) (15.07-2.55) (continuation of excerpt 6)
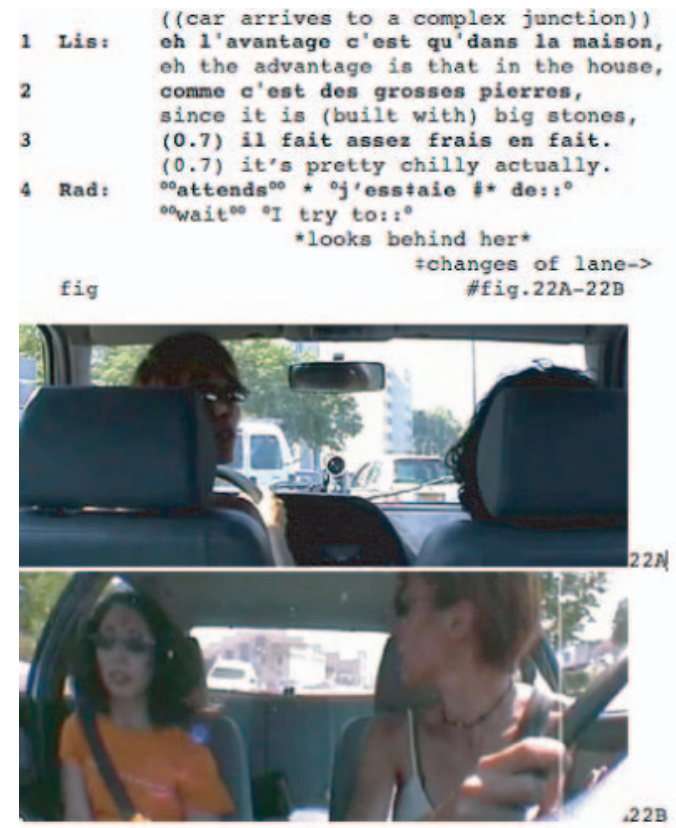


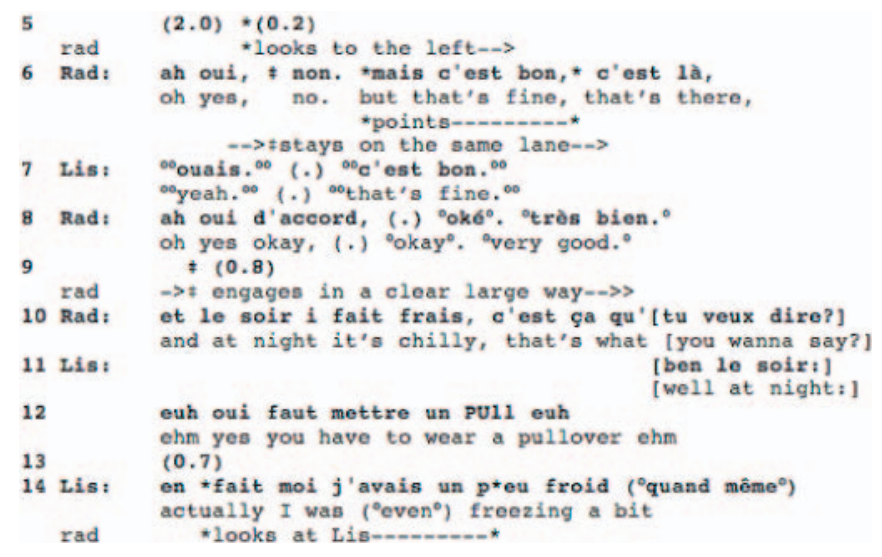

Lisa is talking about her holiday home, saying that it is chilly inside (lines 1-3). Radia does not respond, and instead focuses her attention exclusively on the traffic. Nonetheless, she displays her non-availability in various ways, topicalizing it (with attends "wait," in line 4), formulating in an uncompleted TCU the driving move she is attempting to do (line 4), and intensively gazing at and turning to the traffic behind her (Figure 22A-22B). Again, talking aloud and formulations of the current move orient to the possibility for Lisa to oversee and monitor the current driving activity - but Lisa does not visibly align her conduct with her. In line 6, Radia discovers that she is on the right track. Lisa minimally aligns with the confirmation of the direction, in a lower voice (lines 6-7), and Radia pursues with a positive assessment (line 8) as she engages with a broad dual carriageway (line 9). At that point, having passed the traffic difficulty, she restores the topic Lisa was developing before (lines 10-11), offering the opportunity to go back to it. When Lisa continues it, Radia further displays her availability by looking at her (line 14).

At the end of the episode, Radia retrospectively manifests her orientation to the suspension of the talk and even to her responsibility for having provoked it: in this sense, she seems sensitive to her rights and obligations as a "coconversationalist" which have been momentarily suspended by her rights and obligations as a "driver."

Converging and diverging co-participants' conducts, as well as switches of focus on talking versus the road, show various forms of coordination in a multiactivity setting, either individual or collective, either aligned or disaligned, either foregrounding the talk or foregrounding the driving activity, within different degrees of exclusive involvement in one of these activities. 


\section{Diverging orientations and the management of dispreferred talk}

Divergent simultaneous talking and driving activities are sensitive to traffic conditions but do not merely depend on them, since they also can be exploited as resources in particular sequential environments - namely, in contexts where disagreement and dispreference are emerging (cf. Mondada 2009a for a similar analysis of the refocalization of attention on food in the service of the organization of talk during dinner conversations). The use of the traffic for all practical conversational purposes can exploit features of driving and road environments - such as the difference between being at a stop versus driving, driving in a difficult context, e.g., at a junction versus driving in a straight clear lane - for the management of dispreferred actions.

In this section, I analyze an extended fragment in which multiactivity is exploited within the management of dispreferred sequences of talk. At the beginning of the excerpt, Bea and Ric are talking, while the car is stopped at an intersection without lights, behind another car. When the other car crosses the road, they stop in first position in front of the traffic. Finally they accelerate and engage with a wide lane. These various positions offer different opportunities for their talk: the first requires minimal attention to the traffic; the second requires monitoring the traffic in order to identify a spot to engage with the main road; the third implies non-problematic driving. These opportunities are subsequently convergently and divergently managed by the couple in a way that is not only sensitive to the traffic but also to the sequential organization of talk - as both engage in proposals responded to by rejections, counter-proposals, and final acceptation.

In lines 2 to 4, Ric makes a proposal that, not getting any response from Bea (line 5), is expanded by a new TCU (line 6). During this first pair part and absence of a second pair part, Ric and Bea also assume divergent bodily orientations, Ric looking at the road in front of him and Bea turning to him:

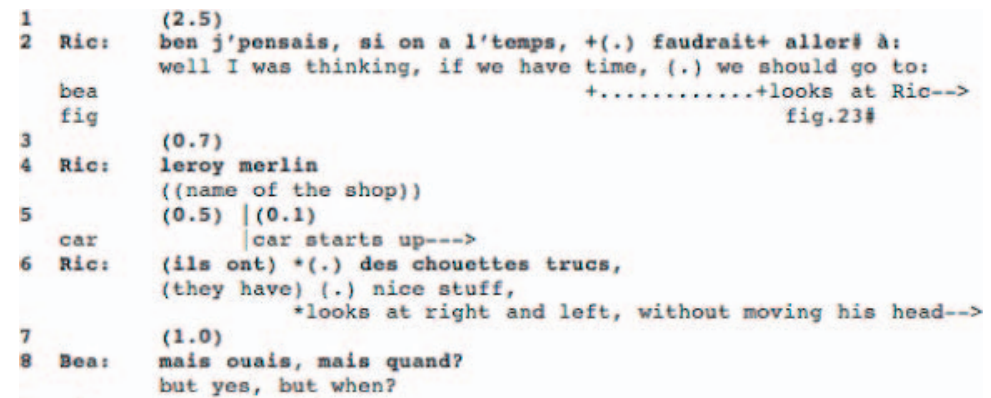




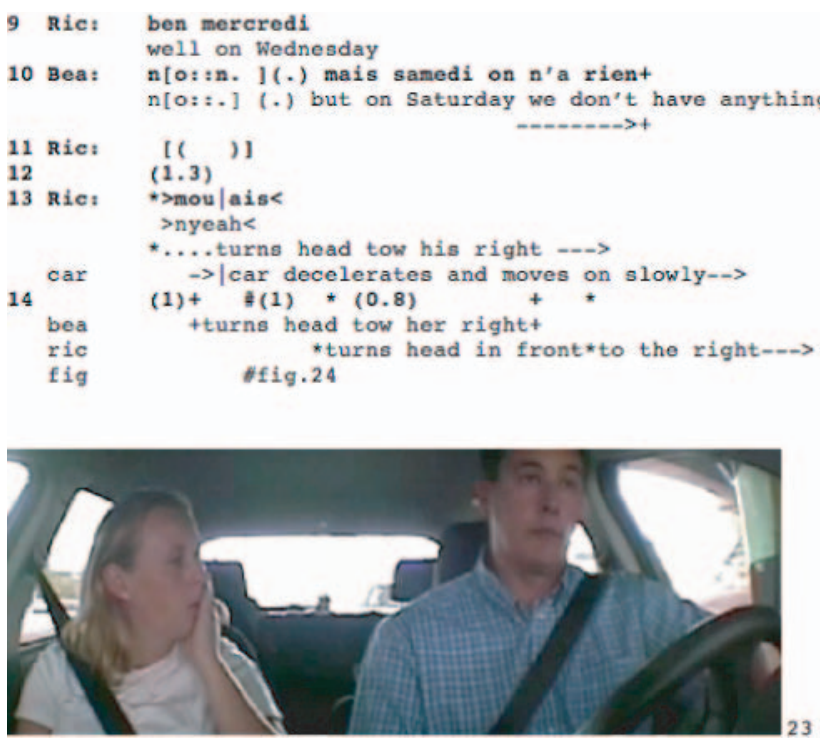

Ric makes a proposal (lines 2-4), after a preface delaying and projecting it. His proposal is constructed within a two-part sentence, comprising a modal verb, and, after a pause, a nominal phrase (line 4). The verb strongly projects the gist of the proposal and attracts Bea's gaze to Ric (Figure 23).

The proposal is followed by Bea's noticeable lack of response (line 5). While the car slowly moves on, Ric adds a new TCU to his previous turn (line 6), offering a new opportunity for Bea to respond. After a long pause (line 7), Bea's response is produced with a delay and in a dispreferred format, beginning with "yes but" (line 8). Instead of accepting or refusing the proposal, she inserts a question/answer sequence about the right time for the proposed joint shopping. Ric answers, mentioning a day (line 9), and Bea responds with a strong disagreement: again, she proposes an alternative day (line 10). Ric's response is delayed, and slightly dispreferred (mouais "nyeah," line 13). Participants' disalignment and disaffiliation are not only displayed by the sequentiality of their talk but also by their bodies: whereas Bea looks at Ric until the completion of the inserted sequence (line 10), Ric's head remains fixedly oriented in front of him, on the traffic. He glances to the left and to the right without moving his head, and, as the car stops and reaches the first position in front of the intersection, he turns his head to the right, looking visibly at the traffic (and not at Bea) - while uttering his mouais "nyeah" (line 13). At the end of the sequence, both Ric and Bea appear to be absorbed in monitoring the traffic (Figure 24), in a convergent and silent way. 


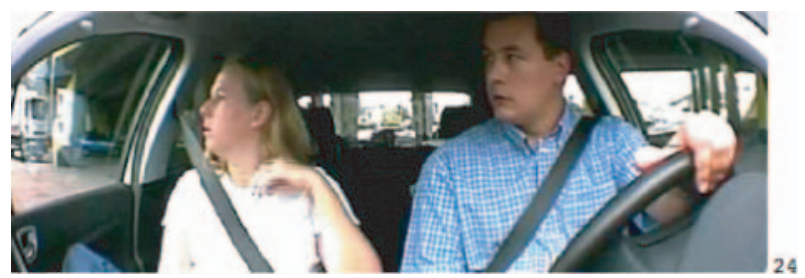

The car's position, in the first line, before engaging with an intersection without lights, offers the opportunity for both participants to display sustained attention towards the traffic and to disengage from a sequential context of talk characterized by dispreference, disagreement and disaffiliation. The conversation is suspended at this point.

But soon Bea launches the proposal again:

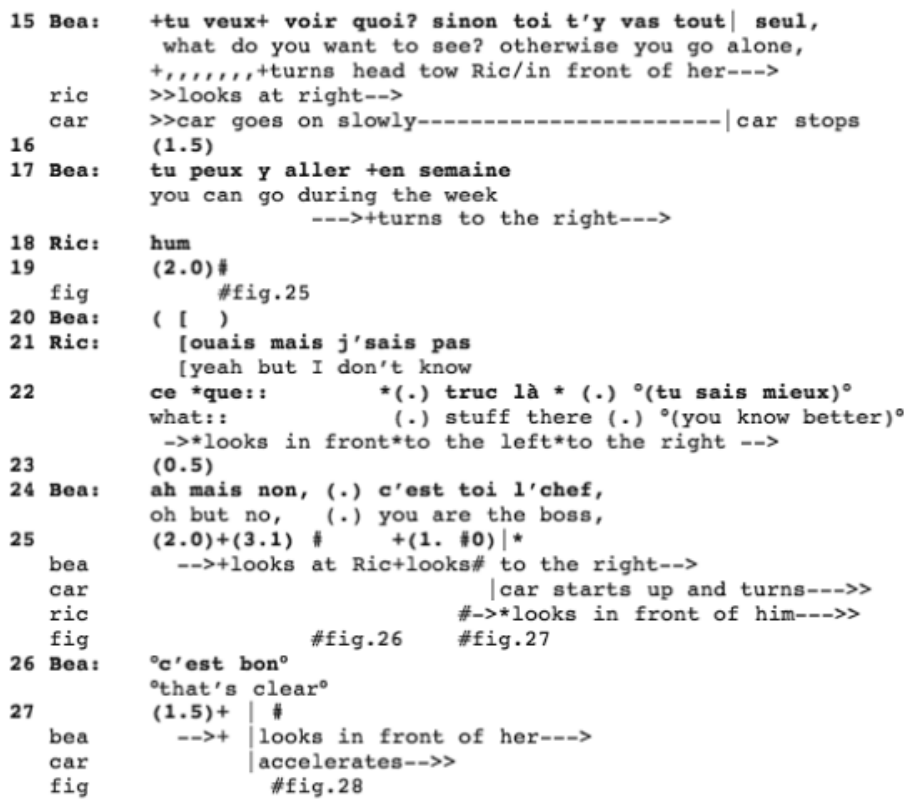




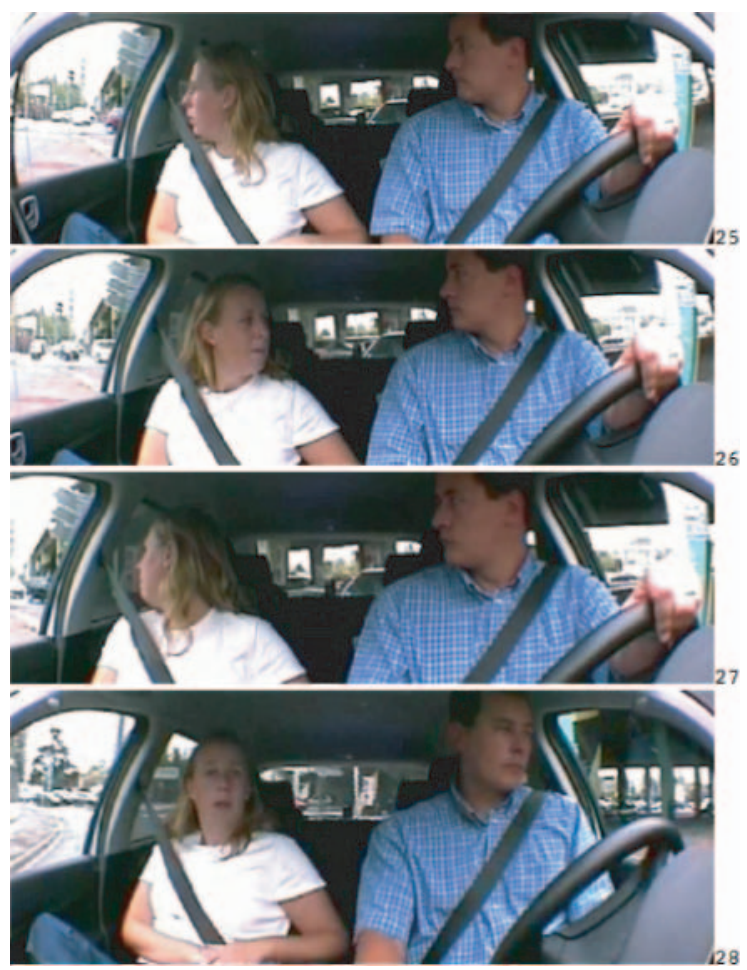

In line 15, Bea comes back to the initial proposal, and queries another detail, concerning not the date but the object of the proposed shopping. She also immediately adds a counter-proposal, suggesting Ric should go shopping alone. Both maintain divergent postures: while speaking, she turns towards Ric, who continues to look on his right, monitoring the traffic. Ric does not respond (line 16) and Bea repeats her counter-proposal, offering a solution to the choice of day (line 17). Ric responds minimally (line 18) and both turn again their heads to the right, now convergently observing the traffic (Figure 25).

After a lapse (line 19), as Bea self-selects (line 20), Ric overlaps by claiming that he does not know (the sentence is left uncompleted, without its syntactical argument) (line 21) and that she knows better (line 22). Bea rebuts him (line 24), ironically categorizing him as the "boss," and staring briefly and provocatively at him (line 25, Figure 26). A long pause follows: he does not respond and they both continue to look at the traffic (Figure 27), until the car moves on. Bea's assessment confirms that the way is clear (line 26), as Ric accelerates. Both look in front of them, at the road (Figure 28). Again, at this point of strong disaffiliation, their attention focuses on the traffic. 
As the car accelerates and engages with the highway, Bea comes back to the issue of shopping, soliciting Ric's account, which is followed by a late agreement:
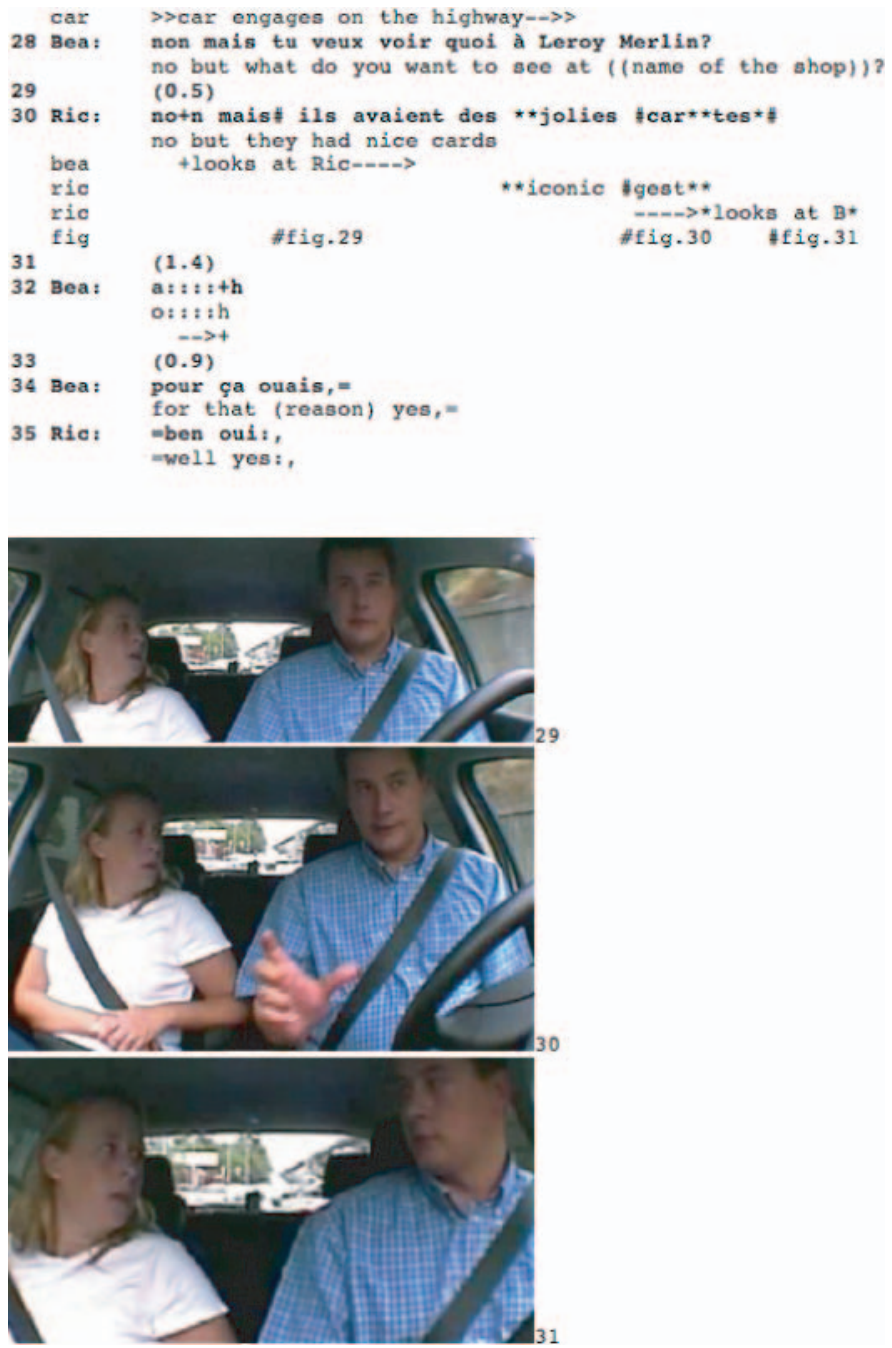

In line 28 Bea asks the same question as in line 15, concerning the purpose of the shopping. Ric answers (line 30) describing the objects he wants to buy, both lexically and gesturally (Figure 30). Their turns begin both with non mais 
"no but," registering the past unsuccessful attempts to reach an agreement. During Ric's response, Bea turns her gaze towards him and he looks at her: mutual gaze is achieved at turn completion (Figure 31). Moreover, his turn is responded to by a stretched and emphatic change-of-state token (line 32), followed by a positive response by Bea (line 34), confirmed by Ric (line 35). At this point, they seem to have reached an agreement and their bodily postures converge within mutual orientation.

In this long fragment, a couple is engaged in a double activity, talking and driving. Driving and paying attention to the street and the traffic are intertwined with the sequential organization of talk: disagreement and disaffiliation are exhibited by divergent postures, oriented in different directions; attention to the traffic not only delays answers, but is used as a resource for not responding in a dispreferred environment. The convergent or divergent coordination of conducts within multiactivity does not just constitute an example of parallel simultaneous activities which can be variously synchronized with talk but a resource for the sequential organization of talk - here for the management of dispreferred actions.

\section{Conclusion}

Multiactivity is a pervasive feature of social practices, in the workplace as in everyday life. In this paper, I proposed a systematic description of the methodic ways in which participants engage together in multiactivity in car conversations, coordinating simultaneous talking and driving in a timed way. Discussions in the literature concerning the management of multiple activities in professional and ordinary settings (section 2) show that participants rely on multiple multimodal resources variously distributed in the environment for organizing and making publicly accountable their involvement in various courses of action. In car conversations, a complex contextual configuration is achieved by participants' glances through the windows, mutual gaze, head movements, bodily postures, oriented both towards the exterior and the interior environment of the car. The paper describes how drivers can display a strong involvement in driving although overhearing the ongoing conversation and eventually joining in (section 3), and focuses on different modes of coordination between driver and passenger, in which they can both accountably be involved mainly in driving or in talking in a convergent way (section 4), or they can maintain divergent main involvements (section 5). These convergent and divergent postures are sensitive to both the traffic conditions and the sequential organization of talk. In the last analyzes (section 6), I show that the former can be exploited to manage particular, troubled, dispreferred moments of the latter. 
Thus, the management of multiactivity can be achieved by the participants in a convergent or in a divergent way: they can mutually align with the production of relevant next actions that take into consideration the same contextual features and display shared attention towards common objects; they can disalign as well, in not attending to the other's talk or in not paying attention to the other's driving efforts.

By paying exclusive attention to driving and not attending to talk, participants also show that their action can be designed as combining various concurrent activities or as being exclusively focused on one of them. Multiactivity settings are characterized by frequent switches between a simultaneous format, where both activities are attended to at the same time, and an alternate format, where one activity is exclusively attended to at a time, while the other is postponed. In car conversations, these switches depend on the participants' reflexive orientation to the traffic, which can be dealt with as requiring more or less attention, as being more or less absorbing. Through their reflexive orientation to the context, they define the kind of activity they are locally engaging in, as well as the priorities they are setting. These orientations to the traffic define moment by moment the mutual relations between the concurrent activities of driving and talking: one can be momentarily foregrounded, as the other is backgrounded, and vice versa. When driving is foregrounded, typically in difficult traffic conditions, talk is minimized; when talk is foregrounded, driving occurs as an ordinary routine.

The last fragment analyzed in the paper shows that this adjustment to the traffic can be situatedly exploited as a resource for the organization of conversation: visibly displaying exclusive attention to the traffic can be a resource for dealing with a dispreferential context of talk. In this sense, there is no unique determination of the difficulty of the road on the conduct of the participants: the demanding nature of the traffic or of space is locally and reflexively defined by the participants in the way in which they select formats for their multiactivity.

In these various regimes of multiactivity, participants display their constant orientation to the sequentiality to talk: when a switch of attention from the conversation to the traffic occurs, when an inserted sequence is initiated to manage some decision to take, its position is sensitive to the organization of the talk going on. It generally orients to the unit's boundaries, such as the completion of the sequence, the turn or the TCU; and when the insertion is done in a particularly abrupt way, its discontinuous character is displayed either by the way in which it is initiated (with excuses, accounts, etc.) or by the way in which it is then reabsorbed (with peculiar resuming techniques). In this sense, the simultaneous management of concurrent conducts in multiactivity does not operate independently of or against sequentiality, but within various sequentially organized courses of action, displaying participants' sensitivity to the progressivity of action. 


\section{Notes}

1. The corpus was collected in 2003 within the EMIC project (Espace Mobilité Interaction Corps) devoted to the study of social interactions in cars. J. Bergena and C. Cance collaborated to the fieldwork. Within the project, another corpus of video-recordings of people visiting cars in showrooms was also collected, as well as another documenting people being instructed about the features of their newly acquired car (cf. Mondada 2009c).

2. The paper adopts Jefferson's conventions for the transcription of talk. An indicative translation is provided line per line in order to facilitate the reading of the French original. The conventions for the transcription of multimodality are sketched in Mondada (2007c):

* * gestures and actions descriptions are delimited between

$+\quad+$ two identical symbols (generally one symbol per participant)

| | and are synchronized with correspondent stretches of talk

$>\quad$ gesture or action described begin before the excerpt's beginning

$--->\quad$ gesture or action described continue after excerpt's end

*---> gesture or action described continue across subsequent lines

---->* until the same symbol is reached

.... gesture's preparation

---- gesture's apex is reached and maintained

,", $\quad$ gesture's retraction

ric participant doing gesture is identified when (s)he is not the speaker

fig the exact point where screen shot has been taken is indicated

\# with a specific sign showing its position within turn at talk.

\section{References}

Brown, B. \& E. Laurier. 2005. Maps and journeys: An ethnomethodological investigation. Carthographica 40(3). 17-33.

Charlton, S. 2009. Driving while conversing: Cell phones that distract and passengers who react. Accident Analysis and Prevention 41. 160-173.

Crundall, D., M. Bains, P. Chapman \& G. Underwood. 2005. Regulating conversation during driving: A problem for mobile telephones? Transportation Research, Part F: Traffic Psychology and Behavior 8F(3). 197-211.

Datchary, C. \& C. Licoppe. 2007. La multiactivité et ses appuis. L'exemple de la "présence obstinée" des messages dans l'environnement de travail. Activité 4(1). 4-29.

De Stefani, E. \& L. Mondada. 2007. L'organizzazione multimodale e interazionale dell'orientamento spaziale in movimento. Bulletin VALS ASLA 85. 131-159.

Drews, F. A., M. Pasupathi \& D. L. Strayer. 2008. Passenger and cell phone conversations in simulated driving. Journal of Experimental Psychology: Applied 14(4). 392-400.

Esbjörnsson, M., O. Juhlin \& A. Wellenmann. 2007. Drivers using mobile phones in traffic: An ethnographical study of interactional adaptation. International Journal of Human-Computer Interaction 22(1-2). 37-58.

Floro, M. S. \& M. Miles. 2003. Time use, work and overlapping activities: Evidence from Australia. Cambridge Journal of Economics 27. 881-904.

Goffman, E. 1963. Behavior in public places. New York: Free Press.

Gonzalez, V. M. \& G. Mark. 2004. "Constant, constant, multitasking craziness”: Managing multiple working spheres. In Proceedings of CHI 2004, 113-120. New York: ATM. 
Goodwin, C. 1984. Notes on story structure and the organization of participation. In M. Atkinson \& J. Heritage (eds.), Structures of social action, 225-246. Cambridge: Cambridge University Press.

Goodwin, M. H. 1996. Informings and announcements in their environments: Prosody within a multiactivity work setting. In E. Couper-Kuhlen \& M. Selting (eds.), Prosody in conversation: Interactional studies, 436-461. Cambridge: Cambridge University Press.

Goodwin, C. 2000. Action and embodiment within situated human interaction. Journal of Pragmatics 32. 1489-1522.

Goodwin, C. \& M. H. Goodwin. 1996. Formulating planes: Seeing as a situated activity. In David Middleton \& Yrjö Engestrom (eds.), Cognition and communication at work, 61-95. Cambridge: Cambridge University Press.

Goodwin, C. \& M. H. Goodwin. 2004. Participation. In A. Duranti (ed.), A companion to linguistic anthropology, 222-244. Oxford: Blackwell.

Gugerty, L., M. Rakauskas \& J. Brooks. 2004. Effects of remote and in-person verbal interactions on verbalization rates and attention to dynamic spatial scenes. Accident Analysis and Prevention 36(6). 1029-43.

Haddington, P. (2010). Turn-taking for turntaking: Mobility, time and action in the sequential organization of junction-negotiations in cars. Research on Language and Social Interaction 43(4). 372-400.

Haddington, P. \& T. Keisanen. 2009. Location, mobility, and the body as resources in selecting a route. Journal of Pragmatics 41. 1938-1961.

Haddington, P. \& Rauniomaa, M. 2011. Technologies, multitasking and driving: Attending to and preparing for a mobile phone conversation in the car. Human Communication Research 37. $223-254$.

Heath, C., M. Jirotka, P. Luff \& J. Hindmarsh. 1995. Unpacking collaboration: The interactional organization of trading in a city dealing room. Journal of Computer Supported Cognitive Work 3(2). 147-165.

Heath, C. \& P. Luff (1992). Collaboration and control: Crisis management and multimedia technology in London Underground line control rooms. Journal of Computer Supported Cooperative Work 1(1-2): 69-94.

Heath, C. \& P. Luff. 1996. Convergent activities: Line control and passenger information on the London Underground. In D. Middleton \& Y. Engestrom (eds.), Cognition and communication at work, 95-129. Cambridge: Cambridge University Press.

Kendon, A. 1990. Conducting interaction: Patterns of behavior in focused encounters. Cambridge: Cambridge University Press.

Kenyon, S. 2008. Internet use and time use: The importance of multitasking. Time \& Society 17. 283-318.

Laurier, E. 2004. Doing office work on the motorway. Theory, Culture \& Society 21(4/5). 261277.

Laurier, E. 2005. Searching for a parking space. Intellectica 41-42(2-3). 101-116.

Laurier, E., Hayden Lorimer, Barry Brown, Owain Jones, Oskar Juhlin, Allyson Noble, Mark Perry, Daniele Pica, Philippe Sormani, Ignaz Strebel, Laurel Swan, Alex S. Taylor, Laura Watts \& Alexandra Weilenmann. 2008. Driving and "passengering": Notes on the ordinary organization of car travel. Mobilities 3(1). 1-23.

Luff, P. \& M. Jirotka. 1998. Interactional resources for the support of collaborative activities: Common problems in the design of technologies to support groups and communities. In Toru Ishida (ed.), Community computing and support systems: Social interaction in networked communities, 249-266. Berlin: Springer-Verlag.

Luff, P., J. Hindmarsh \& C. Heath (eds.). 2000. Workplace studies: Recovering work practice and informing system design. Cambridge: Cambridge University Press. 
McCarley, J. S., M. J. Vais, H. Pringle, A. F. Kramer, D. E. Irwin \& D. L. Strayer. 2004. Conversation disrupts change detection in complex traffic scenes. Human Factors 46. 424-436.

Mondada, L. 2005. La constitution de l'origo déictique comme travail interactionnel des participants: une approche praxéologique de la spatialité. Intellectica 2-3. 41-42, 75-100.

Monadada, L. 2007a. Interaktionsraum und Koordinierung. In R. Schmitt (ed.), Koordination. Analyzen zur multimodalen Interaktion, 55-94. Tübingen: Narr.

Mondada, L. 2007b. Operating together through videoconference: Members' procedures for accomplishing a common space of action. In S. Hester \& D. Francis (eds.), Orders of ordinary action, 51-67. Aldershot: Ashgate.

Mondada, L. 2007c. Multimodal resources for turn-taking: Pointing and the emergence of possible next speakers. Discourse Studies 9(2). 195-226.

Mondada, L. 2008. Using video for a sequential and multimodal analysis of social interaction: Videotaping institutional telephone calls. Forum: Qualitative Sozialforschung/Forum: Qualitative Social Research 9(3). http://www.qualitative-research.net/index.php/fqs/article/view/1161/ 2571 (accessed 14 April 2012).

Mondada, L. 2009a. The methodical organization of talking and eating: Assessments in dinner conversations. Food Quality and Preference 20. 558-571.

Mondada, L. 2009b. Emergent focused interactions in public places: A systematic analysis of the multimodal achievement of a common interactional space. Journal of Pragmatics 41. 19771997.

Mondada, L. 2009c. The embodied and negotiated production of assessments in instructed actions. Research on Language and Social Interaction 42. 329-361.

Mondada, L. 2011. The organization of concurrent courses of action in surgical demonstrations. In: Streeck, J., C. Goodwin, C. LeBaron (eds.), Embodied Interaction, Language and Body in the Material World. Cambridge: Cambridge University Press, 207-226.

Nevile, M. \& Haddington, P. 2010. In-car distractions and their impact on driving activities. Report for a 2008 Road Safety Research Grant, written for the Australian Transport Safety Bureau, Australian Government Department of Infrastructure, Transport, Regional Development and Local Government, Canberra.

Rakauskas, M. E., L. J. Gugerty \& N. J. Ward. 2004. Effects of naturalistic cell phone conversations on driving performance. Journal of Safety Research 35. 453-464.

Recarte M. A. \& L. M. Nunes. 2003. Mental workload while driving: Effects on visual search, discrimination, and decision making. Journal of Experimental Psychology: Applied 2(9). 119137.

Robinson, J. D. 1998. Getting down to business: Talk, gaze, and body orientation during openings in coctor-patient consultation. Human Communication Research 25. 98-124.

Rossano, F., P. Brown \& S. Levinson. 2009. Gaze, questioning, and culture. In J. Sidnell (ed.), Conversation analysis: Comparative perspectives, 187-249. Cambridge: Cambridge University Press.

Sacks, H. 1972. An initial investigation of the usability of conversational materials for doing sociology. In D. Sudnow (ed.), Studies in social interaction, 31-74. New York: Free Press.

Schegloff, E. A. 1998. Body torque. Social Research 65(3). 535-586.

Schegloff, E. A. \& H. Sacks. 1973. Opening up closings. Semiotica 8(4). 289-327.

Stivers, T. \& F. Rossano. 2010. Mobilizing response. Research on Language and Social Interaction 43(1). 3-31.

Strayer, D. L. \& F. A. Drews. 2007. Multitasking in the automobile. In Arthur F. Kramer, Douglas A. Wiegmann \& Alex Kirlik (eds.), Attention: From theory to practice, 121-133. Oxford: Oxford University Press.

Strayer, D. L. \& J. A. William. 2001. Driven to distraction: Dual-task studies of simulated driving and conversing on a cellular telephone. Psychological Science 6(12). 462-466. 
Suchman, L. 1997. Centers of coordination: A case and some themes. In L. Resnick, C. Pontecorvo \& R. Säljö (eds.), Discourse, tools, and reasoning: Essays on situated cognition, 41-62. Berlin: Springer.

Szymanski, M. H. 1999. Re-engaging and dis-engaging talk in activity. Language in Society 28. $1-23$.

Lorenza Mondada (b. 1963) is professor for linguistics at the University of Basel (lorenza .mondada@unibas.ch). Her research interests concern conversation analysis, interactional linguistics, workplace studies, and the study of multimodality. Her publications include the co-edition, with A. Lindström, of the special issue on Assessments in Social Interaction, Research on Language and Social Interaction, 42 : 4, 2009; with T. Stivers and J. Steensig, of Knowledge and Morality in Conversation. Rights, Responsibilities and Accountability. Cambridge University Press, 2011; with P. Haddington and M. Nevile of Interaction and mobility: language and the body in motion. Berlin: De Gruyter, 2012. She has also widely published in journals like Journal of Pragmatics, Language in Society, Discourse Studies, Research on Language and Social Interaction. 